$7-2009$

\title{
What Drives Research-focused University Academics to Want to Teach Effectively?: Examining Achievement, Self-efficacy and Self- esteem
}

Linda Evans

University of Leeds, I.evans@leeds.ac.uk

Maria Bertani Tress

University of Leeds, edmbt@leeds.ac.uk

Follow this and additional works at: https://digitalcommons.georgiasouthern.edu/ij-sotl

\section{Recommended Citation}

Evans, Linda and Tress, Maria Bertani (2009) "What Drives Research-focused University Academics to Want to Teach Effectively?: Examining Achievement, Self-efficacy and Self-esteem," International Journal for the Scholarship of Teaching and Learning: Vol. 3: No. 2, Article 12.

Available at: https://doi.org/10.20429/ijsotl.2009.030212 


\title{
What Drives Research-focused University Academics to Want to Teach Effectively?: Examining Achievement, Self-efficacy and Self-esteem
}

\begin{abstract}
What motivates research-focused academics, employed at a leading research university, to want to teach well - particularly considering that many of them admit to prioritising research above teaching? Why do they not simply settle for expending as little time as possible on their teaching planning and preparation, delivering run-of- the-mill, lack-lustre seminars and lectures that fail to inspire their students? These are the central questions addressed in this article, which revisits and re-analyses data from a 1993-4 case study of teaching and learning in a UK research-intensive university. Selected qualitative data from the original study are used to present an overview of the attitudes toward teaching of, and the teaching approaches used by, eighteen academics, and these data are supplemented by up-to-date follow-up data gathered in 2009. The picture is one of effective - often innovative - teaching carried out conscientiously. Yet the teachers are, by their own admission, first and foremost researchers. What, then, motivates their teaching? Applying what we call 'feasibility-determined analysis', we hypothesise that the academics were motivated by self-esteem needs, which, in turn, were fed by self-efficacy beliefs and the pursuit of a sense of achievement. Finally, we briefly discuss the wider implications of this hypothesis for professional development in higher education contexts.
\end{abstract}

\section{Keywords}

Motivation (in academics), Self-conception, Self-esteem, Self-efficacy, Teaching excellence (in higher education)

\section{Creative Commons License} c) (i) $\Theta$

This work is licensed under a Creative Commons Attribution-Noncommercial-No Derivative Works 4.0 License. 


\title{
What Drives Research-focused University Academics to Want to Teach Effectively?: Examining Achievement, Self-efficacy and Self-esteem
}

\author{
Linda Evans \\ University of Leeds \\ Leeds, England, UK \\ I.evans@leeds.ac.uk \\ Maria Bertani Tress \\ University of Leeds \\ Leeds, England, UK \\ edmbt@leeds.ac.uk
}

\begin{abstract}
What motivates research-focused academics, employed at a leading research university, to want to teach well - particularly considering that many of them admit to prioritising research above teaching? Why do they not simply settle for expending as little time as possible on their teaching planning and preparation, delivering run-of- the-mill, lack-lustre seminars and lectures that fail to inspire their students? These are the central questions addressed in this article, which revisits and re-analyses data from a 1993-4 case study of teaching and learning in a UK research-intensive university. Selected qualitative data from the original study are used to present an overview of the attitudes toward teaching of, and the teaching approaches used by, eighteen academics, and these data are supplemented by up-to-date follow-up data gathered in 2009. The picture is one of effective - often innovative - teaching carried out conscientiously. Yet the teachers are, by their own admission, first and foremost researchers. What, then, motivates their teaching? Applying what we call 'feasibility-determined analysis', we hypothesise that the academics were motivated by self-esteem needs, which, in turn, were fed by self-efficacy beliefs and the pursuit of a sense of achievement. Finally, we briefly discuss the wider implications of this hypothesis for professional development in higher education contexts.
\end{abstract}

Keywords: Motivation (in academics); self-conception; self-esteem; self-efficacy; teaching excellence (in higher education)

\section{Introduction}

It is fairly easy to see how faculty may be committed and enthusiastic teachers in a university where teaching is the prime focus: an institution such as that described by Macfarlane and Hughes (2009) as the UK's lowest ranked university on the basis of research activity, but one with a strong teaching focus. As these authors explain, the uphill struggle facing educational developers in this institution was that of 'turning teachers into academics', in an attempt to realize an increasingly research-focused aspiration ( $p .12$ ). But what about the context representing the other extreme: highly research-focused academics employed at leading, research-intensive universities? Are such academics likely to be committed teachers, or do they perceive teaching as a rather inconvenient and unwelcome distraction from what they consider to be their main raison d' être - research? 
This was one of the issues incorporated into the research agenda of a project undertaken by one of us several years ago: a case study of undergraduate teaching and learning in one of the UK's top ten research universities. The purpose was to examine both academic faculty and student perceptions of the extent to which the teaching and learning in which they participated was effective at meeting their respective needs: job-related needs in the case of faculty; study-related' needs in the case of students. Relatively negative attitudes toward teaching on the part of the sample of twenty academics had been anticipated: attitudes reflecting such prioritization of research that teaching was, by comparison, side-lined in terms of the time and effort expended on it. The findings uncovered quite a different picture.

It is this refreshingly surprising picture that is the focus of this article. We elaborate on the picture, and then seek to explain it. In doing so we address the key question that our paper addresses: what motivates research-focused academics to want to teach effectively?

\section{Re-Visiting the Study: Details and I ssues}

We present a re-analysis of data gathered fifteen years ago. To help address specific methodological issues that this raises, we supplement these re-analysed data with current data, which we introduce and explain later. First, to set our re-analysis in context, we outline the original study's design and relevant findings.

\section{The Original Research: Rationale and Design}

The study, whose design and findings are presented in detail in Evans and Abbott (1998), was prompted by a contemporary debate (in the mid 1990s) within the higher education community on the quality of its teaching. The purpose of the original research, conducted over twelve months, beginning in 1993, was shaped by concern not only that sweeping assertions about generally poor teaching lacked a convincing evidential basis, but also by the implications for academics' workloads of the teaching improvement agenda. It seemed that academics were in danger of being asked to do more and to do it better, with no convincing evidence that what they were being asked to fix was, in fact, broken. The 1993-4 study was thus conceived as a mechanism for providing a small evidential contribution to the debate.

Conducted by one of us and a research partner, the small-scale study employed convenience sampling to identify as a suitable case a research-intensive, 'old' university in the UK (i.e. one that had enjoyed university status before the end of the binary divide in 1992, when polytechnic colleges were given university status). The research objectives were focused on uncovering two perspectives: that of undergraduate students and that of academics representing four subjects: physics, law, education, and English and American studies. We confine the information presented here to the academic perspective. A limited budget prevented our extending the study to include postgraduate teaching and we recognize that this necessarily limited scope may reduce the findings' applicability to the full spectrum of teaching and learning in higher education. Our discussion in this paper relates to data that reveal the attitudes and perceptions of eighteen academics who, as a result of the purposive sampling employed represented a range of evident attitudes to both teaching and research: those whose commitment to and enthusiasm for their research bordered on obsessiveness that reflects workaholism, through to those who struggled to find the time to maintain what they considered a respectable research output. Yet, being employed by a research-intensive university, they were all research-active and research-focused, and fully 
compliant with expectations of them to undertake research, identifying it as a key component of their work.

Semi-structured interviews were used to collect qualitative data that addressed the research questions (full details of which are presented in Evans and Abbott, 1998, along with details of the data analysis process). The main thrust of the research questions in relation to the sample of academics was directed at identifying: their perceptions of undergraduate students' study-related needs and preferences and of the extent to which these are met; the implications for course and teaching effectiveness; the nature and features of their teaching and the factors that underpin these; the extent to which their chosen teaching approaches and organizational strategies constrain or enable them in their work as a whole; and the impact of these issues on their job satisfaction.

\section{The Refreshingly Surprising Picture: Relevant Selected Findings of the 1993-94 Research}

As we have indicated, somewhat contrary to what was anticipated, a picture emerged from the study that is at odds with the over-simplistic, stereotypical image of ivory tower academics whose pre-occupation with their research makes them reluctant and ineffective teachers. By means of elaborating on this unanticipated picture we present specific findings relating to the academics' preferentially-based distinction between, and relative prioritisation of, teaching and research; their attitudes to teaching; and the nature and evident quality of their teaching.

Priorities and preferences

Research was identified by all eighteen academics as enjoyable and a source of fulfilment. Six gave teaching and research equal ranking, but for the majority of the sample research was identified as the most enjoyable and fulfilling part of their work, as expressed by Maurice", an English and American studies academic: 'I think, in terms of pleasure, at the moment, I would place research at the top ... I would probably put it in: research, teaching, administration, order'.

Nearly forty years ago Halsey and Trow's pioneering research into academics' professional lives identified a typology of attitudes, which included a dimension that those authors identified as relating to the basis of teaching and research orientations, that is: 'to conceptions of the university teacher's primary role as either a creator of knowledge or as a teacher and transmitter of values and culture' (Halsey and Trow, 1971: 455). For the eighteen academics in the 1993-4 case study any such duality was evidently less dichotomised than is implied in Halsey and Trow's analysis. Corroborating Becher's (1989) findings, many spoke of the 'synergy' between research and teaching and of how various aspects of their teaching (in some cases preparation and planning; in other cases, delivery) had made useful contributions to their research.

Despite a predominant preference for research, the majority of the sample made it perfectly clear that they valued and enjoyed teaching. In the research interviews they had been asked to consider what their ideal jobs might look like: what specific components these would incorporate. The case study researchers had anticipated being presented with many pictures of research-only, teaching-free 'ideal' jobs, but this was not the case: sixteen academics included teaching as a constituent of their ideal job. Moreover, the candour of these interviewees in discussing other, rather contentious, issues and in not shying away from risking presenting themselves in what may be considered a bad light, implies that they were unlikely to have been motivated by wishing to give the appearance of doing 
and saying the 'right' things.

Attitudes to teaching

In the 1993-4 research, 'teaching' was interpreted broadly, as any activity related to interaction and/or communication with students for the purpose or with the result of providing elucidation on and/or transmitting course-related knowledge. This therefore includes exchanges of the kind that some (around half the sample) of the academics were keen to avoid or restrict: impromptu, unscheduled, and what these academics often considered unnecessary, face-to-face approaches to them for help or guidance - what they referred to as 'students coming knocking on the door'. Some, in fact, spoke of 'fobbing off' students, and several reported sticking rigidly to office hours: one remarked that one hour a week was 'more than enough time' for engaging with students in this manner. This is a mode of casual communication that has now, fifteen years on, been greatly superseded by the proliferation of email. Yet in 1993-4 the academics were divided on this issue. Several (around half) did not object to such interaction; some reported that they encouraged it, while others implied that their willingness to be available, in various manners and under a variety of circumstances, reflected a sense of duty or responsibility.

A concern for quality

Where there was unanimity, however, was in relation to the academics' evident concern for the quality of their teaching, in the sense of course delivery. Whatever their other commitments and pressures, interviewees' descriptions and explanations of how they tackled this component of their work conveyed a clear impression of a group of very conscientious professionals who generally set high standards for themselves in relation to planning, preparation and delivery. Even those who had identified teaching as less important to them than other aspects of their job clearly endeavored to teach to high standards. Meryl, for example, provided the most negative assessment of teaching as a job component:

I think I am one of those people who prefers research to teaching, although I feel sad to say that. When I came to this university I found - and, frankly, I still find - the students actually rather boring. I don't know anything about the students ... and I ... I can tell I'm not really interested in them because I can't remember their names - d'you know what I mean? There's a Sophie and a Celia sitting next to each other, and I can't remember the difference between them. ... I can see that, y'know, in all sorts of ways, my role as a teacher is still important, but, actually, I find less satisfaction in my teaching than I ever did. And I think that's getting worse. So, yes, I think, probably, if I'm being honest, I would say that I would prefer to be quietly doing my research.

Yet she nevertheless presented herself as a conscientious teaching practitioner:

I think my relationship to teaching is so difficult because I'm always so selfcritical. I really am very critical about my own teaching, and I know, much better than they do, what's wrong with what's going on, and I know when the seminars are getting dull ... I'm very sensitive to that. So, I'm much more agonised by that than they are. They're probably just sitting there thinking, 'Oh,' y'know, 'I wish this seminar would end', or, 'I wish it would pick up in some way.' But, for me, that's real agony ... y'know ... I'm still very caught up in teaching (Meryl, English and American studies tutor). 
The general conscientious approach to teaching manifested itself in ways which suggest that it was underpinned by a concern to be professionally competent, rather than by a love of the activity itself. Several academics complained, for example, about aspects of teaching (interpreted in its widest sense) which they disliked, whilst still wanting to do the job to the best of their ability. One was dissatisfied with having to spend time writing notes to students who failed to turn up to classes, all the while recognising that this was integral to the caring, interested persona that she genuinely wished to assume. Similarly, recentlyappointed tutors spoke of their anxiety to establish themselves as competent teachers, even, in some cases, at the expense of the more highly-valued research:

In the first term I didn't even think about doing any research - I just wanted to survive to Christmas, basically. I find the teaching time manages to take up most of the time in here, just now (Brian, law tutor).

I am relatively research-focused, but I am very concerned about my lectures. If I have a lecture I ... er ... I get nervous and I start working very hard so I can get this lecture done and I regard these lectures almost as an article I have to write ...I notice the same with most of the young colleagues. If they have a lecture on Tuesday they'll start working on Friday and work right through the weekend to get the lecture done. It's the major event in the week (Otto, law tutor).

Moreover, these conscientious attitudes manifested themselves in the academics' concern to maintain standards through innovative, imaginative and creative practice. When asked to consider the extent to which their teaching was innovative, the sample of eighteen provided thirteen specific illustrative examples. Avril, for example, a law (full) professor with a strong international research profile, described a board game that she had devised as an aid to teaching the law statutes, and Jenny, an education tutor, spoke of introducing weekly debates into her classes. Even Meryl, whose rather negative comments are quoted above, evidently took pride in her delivery and relished its success:

I was giving a lecture on A Street Car Named Desire, by Tennessee Williams, and I played the video of the film silently behind me as I lectured, so they could watch it, instead of having to look at me. And they were obviously knocked out by that - it obviously worked really well. And, in fact, it was absolutely perfect because - and this was not planned - but it actually ... when I finished my lecture, Blanche Dubois was actually saying, 'Good-bye' to somebody, so I turned up the sound and she said, sort of, 'Adios, adios', and I thought, 'I couldn't have done it better if I'd planned it!' But I like it when I do something new that's different. The second time I do that ... I'll probably do that again next year, but I'll be bored by it ... y'know (Meryl, English and American studies tutor).

The overall picture

Sketched out above, then, is an overall picture of a group of academics who take teaching seriously. Certainly, this seriousness does not, in some cases, extend to prioritisation of teaching duties and responsibilities above research, nor does it extend to some of those components that are incorporated into teaching in its widest sense, such as engaging with individual students who seek unexpected or uninvited consultations. In this respect the picture is rather fragmented. Yet in relation to planning and delivering course content it is uniform, portraying an academic workforce that strives not merely for effectiveness, but 
for excellence. This is a workforce that would have no trouble passing itself off as teachingfocused, indistinct - at least ostensibly - from any workforce in a 'teaching' university.

But how accurate is this picture today? Do the evident views and perceptions of the case study sample resonate with experiences of working life within $21^{\text {st }}$ century academia?

\section{Years On: Updating the Picture}

The first submission of this article prompted an observation from one of the reviewers:

I struggled with understanding how reanalyzing the findings has the same level of relevance today. The results and conclusions that are reported are meaningful only to the extent to which I can assume that issues and context of institutional priorities, faculty roles and rewards, the evaluation systems used to judge faculty, and teaching conditions have a similar impact on faculty today as they had 15 years ago.

This is an entirely valid criticism. If the 'refreshingly surprising picture' that we have presented of academic life in the 1990s in a research-intensive British university is no longer authentic today then it represents a historical artifact rather than an examination of issues that are current and enduring, and the relevance of our discussion and conclusions is correspondingly diluted. We therefore decided to address this issue head-on by gathering supplementary, up-dated, data from the original sample.

\section{The Original Sample's 'Postscript'}

Our reviewer questioned whether the original eighteen academics, several of whom are quoted above, would convey the same messages if they were asked the same questions today and were having to consider these questions within institutional and professional cultural contexts that, potentially re-shaped by new priorities and foci, are likely to be quite different from those that provided the backdrop to their perspectives and perceptions of fifteen years ago. Sharing her/his concern, we sought to provide him/her with a precise answer by re-contacting the original sample and asking them directly. Without funding at our disposal we did not propose to re-interview them face-to-face, as in the original study, but merely to explain to them the issue concerning us and to seek their views through telephone or email communication, undertaken by the original researcher (Evans) only, in order to ensure continued confidentiality by preserving anonymity. These were not intended to be 'full blown' research interviews, but to follow the same broad format as, and have a similar purpose to that of, the re-contacting of research subjects that is sometimes incorporated into research projects in order to seek verificatory support for the researcher's analyses and emerging conclusions.

The whereabouts of around half the sample were known to one of us through the informal networking system that is integral to any national or subject academic community. Two (both physicists) were known to have died; several academics were still employed at the case study university; several had moved on (including one to our own university); four had retired; one had moved abroad, and several - including Meryl - could not be traced within the time available. Nine were re-contacted, but two failed to respond to email and telephone messages, leaving seven who constituted what we hitherto refer to as the followup sample, who provided supplementary data as intended. 
By email the research subjects were greeted and reminded of their participation in the original study and asked if they were willing to spend around 10-15 minutes discussing a few follow-up issues in order to update the dataset. They were told that the original researcher would ring them within two days, and of the intention to draw upon their anonymised comments in publications. (Five responded and agreed, though one asked for the update to occur by email since he would not be on campus to receive the call; the remaining two were eventually contacted by telephone, whereupon their agreement was secured.) The research subjects were then each sent: a copy of this article in the form in which it had been first submitted for publication, with relevant sections highlighted (though we felt it would impose too much upon subjects' good nature to ask them to read the entire article, by this means it was available to them and we hoped some would read it all), and a copy of relevant comments that each of them had made during the 1993-4 interviews, together with corresponding interview questions. A day or two later the subjects were recontacted by telephone, and in one case by email, and asked to discuss whether they considered their working contexts to have changed in ways that potentially impacted upon their views and perceptions of teaching and their attitudes to this aspect of their work, and whether their views, perceptions and attitudes had - by any process - changed since the mid-1990s, and, if so, what was the nature and extent of any change. They were asked if they would respond differently today to the same relevant questions as asked originally.

All seven subjects are employed at research-intensive universities, which are ranked (as a result of the 2008 UK research assessment exercise) as being among the top twenty UK universities. Four such institutions were represented within the sample. (One subject had, in the intervening years, worked for two years at a lower-ranked, teaching-focused, university.) Space restrictions preclude anything other than the briefest of summaries of the follow-up sample's comments; a more expansive presentation, including individuals' reported comments, must be the subject of another paper. Interestingly, though - and perhaps contrary to some of our reviewer's expectations - their views do not appear to have changed significantly since the mid-1990s. The reason for this is probably that their contexts do not, in fact, by their accounts, appear to have changed significantly. Two academics implied broad agreement with our reviewer's observation that 'in recent years... an increasing emphasis on documenting student learning for institutional accreditation, evaluation of faculty effectiveness, changes in funding patterns, and ranking of student performance have changed institutional priorities with regard to teaching and faculty workloads' (anonymous reviewer). Five were less convinced that any such changes had impacted directly upon them: one implied that there was 'a lot of rhetoric' but not as much impact on policy as might be expected; two observed that their institutions had always, at administration level, taken teaching seriously, but not to 'silly proportions' and that this, from their perspective, had not noticeably changed. The key issue appears to have been that prioritisation of research within these academics' current institutions remained undiluted. Two academics representing different institutions commented that teaching had, in recent years, been given noticeably greater prominence by administration, but that this had not eclipsed the prioritisation of research and that no significantly greater pressure had been placed upon them to perform as teachers than had been in place in the mid-1990s. One commented that there was now less 'second class citizenship' associated with teaching (excellence), and since this point was hereafter raised by the researcher in subsequent 'interviews' and the observation was then echoed by the four academics that remained to be questioned, we return briefly to and expand upon it in a later section.

It is perhaps significant that four of the seven follow-up sample are now full professors with relatively limited teaching roles, but these four nevertheless denied that extensive 
institutionally-imposed pressures or culture changes had been noticeable during the intervening years - though this may be an illusion; imposed gradually, such changes may have been imperceptibly incorporated within institutional culture and assimilated by the academics. One law professor summed up the situation that perhaps prevailed in all four institutions: that research was, and is, 'the bottom line'; that this is 'the name of the game' and that her institution, having carved out a place for itself in the highest echelons of the prestigious research-focused 'Russell Group iii gang' was not going to risk jeopardising its position, or its ranking.

Rather than rigorous data collection, this communication with the follow-up sample represents what may best be described as casual, elucidatory-directed conversational inquiry, undertaken within a limited time scale for a specific narrow purpose. As far as it goes, this most recent snapshot presents a very similar picture to the larger overall one drawn from mid-1990s data. Yet this evident broad conformity surprises us because it conflicts with literature suggesting that there are indeed subtle signs of research-focused academics employed in research-intensive universities tending to take their teaching roles and responsibilities increasingly seriously (see, for example, Wright, 2005), typically in response to institutional initiatives and pressure (Boshier, 2009) - a point highlighted by our anonymous reviewer. Though, interestingly, this re-prioritisation trend - if, indeed, it exists (Boshier, 2009) - does not necessarily go hand-in-hand with re-evaluation of teaching on a preferential basis (Deem and Lucas, 2007). There are clearly mixed messages being conveyed, for Skelton (2005) writes of the impact on academic practice of new managerialist cultures in the academy, which threaten student-centred activity, whilst Deem and Lucas (2007) applying a Bourdieuian analysis to their study of academic life in five UK universities, conclude that a majority of their sample 'valued (and thought their departments valued) scientific capital more highly than teaching capital' (p. 129). These mixed messages may reflect the different perspectives of, on the one hand, participants in a process (who may be too close to the 'action' to see it clearly) and, on the other hand, analysts of it (whose view from afar may afford them a fuller picture): a phonemenologically-based dichotomy that fails to validate either perspective over the other. Moreover, we fully acknowledge that our hastily-applied and necessarily abbreviated 2009 supplementary data collection potentially falls short in many respects as a reliable elucidatory device. A larger scale, more structured study may certainly reveal a different picture of twenty-first century academics' attitudes and motivations toward teaching.

But what accounts for this picture that we have uncovered and, moreover, have had albeit potentially contentiously - verified? For it is on this picture that our analysis must focus.

\section{Understanding the Picture: What Drives Research-focused University Academics to Want to Teach Effectively?}

Our starting point is briefly to consider motivation: what it is and how it operates. This allows us to put together a framework for understanding the impetus for human activity specifically, professional activity in a workplace context - upon which to build a rational and feasible explanation for what, fundamentally, motivated the teaching attitudes and behaviors of the eighteen academics in the 1993-4 case study. Finally, we briefly examine the extent to which this proposed explanation has wider applicability beyond the case studied, and its contribution to the scholarship of teaching and its knowledge base. 


\section{Motivation: the Concept and the Process}

Conceptual analyses and definitions of motivation are less plentiful than examinations of what it encompasses and what its constituent features are. Neither Herzberg (1968) nor Maslow (1954), for example, whose work is generally considered seminal (if contentious at least in the case of Herzberg), provides an explicit definition.

Evans (1998) makes the point that motivation is differently defined according to application of the term: whether it is considered as a causal force, a prevailing state of mind or attitude, or an activity (intended to precipitate a causal force). We adopt her stipulative definition of motivation as: a condition, or the creation of a condition, that encompasses all of those factors that determine the degree of inclination towards engagement in an activity (Evans, 1998, p.34). Contextualising this definition within, and adapting it to, our analysis, our focus therefore becomes consideration of what are the factors that underpinned the eighteen academics' concern to teach effectively. This concern - that is, the degree of the academics' inclination towards effective teaching - has been established in the discussion above.

But, at a more general level, what determines the degree to which people are inclined toward any activity? Herzberg (1968) contends that workplace motivation may be influenced by any one or more of five specific motivation factors: achievement; recognition (for achievement); advancement; responsibility; and, the work itself. In her conceptuallybased critique of Herzberg's motivation-hygiene theory, Evans conflates these five factors into one: achievement, arguing that it represents a different classificatory level from that of the other four, since they either contribute to or reinforce individuals' sense of achievement. They are, therefore, part of achievement's ontological composition. Evans's isolation of achievement as the fundamental motivating factor corroborates Steers et al's (1996, p. 19) observation:

The need for achievement is perhaps the most prominent learned need from the standpoint of studying organizational behavior. The challenging nature of a difficult task cues that motive which, in turn, activates achievement-oriented behavior.

Accepting and applying to our analysis Evans's identification of individuals' sense of achievement as the driving force behind their workplace behavior, we now turn our attention to consideration of what form that driving force took in the case of the eighteen academics in question.

\section{The Academics' Desire to Achieve: Examining Motivation in Context}

What makes Meryl - bored and tired with routine, uninterested in her students, and, as she confessed in her research interview, eager to 'fob them off' when they unexpectedly come knocking at her door - want to teach well? Meryl is ambitious, research-focused and with a growing international reputation as an expert in the literature of the American south. So why does she not simply focus unwaveringly on her research, on strengthening her profile and her overseas networks, and spend as little time as possible on teaching preparation and planning, then turn up for classes and churn out enough dull material to last the duration of the session, unconcerned with how boring and uninspiring the students may find it? That she does not do this was evident from her research interview. From the brief extracts presented as her quotes, above, we find that she worries about the quality of her teaching, is anxious that her seminars engage students, and is gratified when her innovative ideas for 
What Drives Research-focused University A cademics

lecture delivery enthral the audience. Why is this? As a teacher, what makes Meryl tick? and what makes her seventeen research-focused colleagues tick?

Here it is useful to draw a distinction between teaching as interpreted broadly (that is, as any activity related to interaction and/or communication with students for the purpose or with the result of providing elucidation on and/or transmitting course-related knowledge) and teaching as interpreted more narrowly as course delivery through lectures or seminars or their equivalent format (examples classes, in the case of the physics sample). This distinction, as we have shown, was an evident basis for differentiation in relation to attitudes and behavior among the sample of academics. Since it was only course deliveryfocused activity that the academics were universally evidently keen to do well at, we restrict the focus of our analysis to this narrower interpretation of teaching, implying it in our discussion. Moreover, it is, after all, the motivation of the Meryls of academia that we are seeking to understand the most - those who admit to generally prioritising research above teaching and whose evident keenness to perform well at teaching does not consistently, if at all, extend to the 'subsidiary' elements of it.

There are, of course, several possible factors that, entirely or in part, independently or in combination, may have motivated the academics, and we emphasise that we do not imply, in the discussion that follows, that one single factor accounts for their attitudes and behavior. What also needs to be borne in mind is that there are inevitable methodological limitations with our process of arriving at a propositional explanation. The a posteriori analysis that we apply draws upon empirical evidence collected some fifteen years ago, supported by recently collected up-to-date evidence. The original dataset consists of audio tapes of original research interviews, averaging one hour's duration per interviewee, and these have been re-analysed in the search for relevant data that may have been overlooked in the original analysis on the grounds of its having then been irrelevant to the research questions. This reanalysis yielded very little new relevant material. What we are left with, then, is the opportunity to make sense of the original data in relation to addressing a question that, in the specific form that we address it, was not explicitly included in the original research questions. Certainly, issues related to this question - what motivates research-focused academics want to teach well? - were raised during data collection in 1993-4, but not as a central issue. We address it here because one of us - one of the original researchers (Evans) - was prompted to do so when, as a result of discussions with a doctoral student (Bertani Tress), a possible explanation, fifteen years after the event, suddenly and unexpectedly presented itself. We recognise, however, that we are necessarily confined to what may best be called 'feasibility-determined analysis', which involves supplementing the data at our disposal with informed reasoning that is framed within and informed by consideration of how feasible our proposition is.

More explicitly, feasibility-determined analysis parallels Evans's (2002, pp. 146-150) recommended component of a research data analysis process directed at 'telling it as it is': that is, presenting as 'unblinkered' and unbiased a perspective as possible. Briefly, feasibility-determined analysis involves, first, brainstorming in order to list as many potential explanations for research findings as may be conceived of, then sifting through the list in order to retain or eliminate items on the basis of their feasibility, which is defined as the possibility and likelihood of their causality within the context and circumstances known to apply to the case being examined. There are degrees of structure and precision that may be applied to the sifting stage, ranging from the relatively unstructured reliance on nothing more than 'hunches' to determine relative feasibility and to identify the most feasible explanation(s), to the application of ('hunch'-informed) numerical ranking of listed items 
(which may, to enhance rigor, incorporate inter-ranker reliability measures) before discarding all listed items below a specified numerical rank, leaving only the most feasible explanation(s). The process is not necessarily confined to identifying only one, or a very small number of, feasible explanation(s); in many cases all feasible explanations may be identified. The criterion for feasibility is whether the identified explanation prompts an affirmative response to the question: is this a possible reason for why/how $x$ occurred? We fully acknowledge that our feasibly deduced hypothesis, presented below, is one of several potential (interrelated) explanations.

Feasibility-determined analysis does, of course, involve going beyond the data and, moreover, it represents what is predominantly circumstantial evidence. We present the results of our analysis as propositional knowledge, but nevertheless believe that it makes a useful contribution to the knowledge base.

\section{The Potential Motivating Factors: a Feasibility-determined Analysis}

In terms of what motivated the academics to want to teach well, it is worth considering the possibility that external pressures, in the form of institutional or departmental culture, may have come into play. This may potentially occur within working contexts where teaching is explicitly prioritised, such as in teaching-focused universities. In such contexts academic faculty may reasonably be expected to buy into institutional culture and the ideologies and values that it represents. If they do not buy into this then they are at least likely to manifest conformity, even if this constitutes simply going through the motions of doing so. Yet, from all accounts, the university in question was not only explicitly and unashamedly researchfocused, but also - at least at the time of the study - it afforded teaching lower priority. This research bias was evident in the institutional promotions policy:

Everybody, to a man, realises that the way to get promoted is to do good research and sacrifice teaching. ... Er ... but some people, nevertheless, do a very conscientious job in the teaching and put a lot of time into it. ...It's just that the research side produces the promotions, whereas the teaching side does not (Bernard, physics tutor).

I think that one of the tragic things about the whole promotion process at this university is that ... what is not rewarded, is things like ... er ... the sort of people - and I'm not talking just about myself here, actually, 'cos I'm talking very much about other colleagues who've not been promoted - the sort of colleagues who are anxious to introduce new courses, who are anxious to make changes, who do re-write their lectures, who do, sort of, take their teaching very seriously, and regard, y'know, a course that's been run in the same way for five years as a real failure (Meryl, English and American studies tutor).

It is therefore unlikely that in the 1993-4 study the eighteen academics were motivated by institutional pressure. Our most recent supplementary data collection (outlined above), however, revealed that in all four institutions represented within the follow-up sample (which include the original case study university), teaching was now rewarded through promotions policy. Though Bernard, quoted above, has sadly died in the intervening years, the 2009 follow-up sample was referred to his remark and asked to comment on his view that the path to promotion lay in sacrificing teaching. They were unanimous in agreeing that this was no longer the case. Nevertheless, consensus among this sample was that, despite higher prioritisation of teaching than occurred fifteen years ago at the case study university, their current institutions all 
What Drives Research-focused University A cademics

exuded cultures of research focus and research excellence, and that, within the higher echelons of wider academia, it was research profile rather than teaching excellence that represented the key esteem indicator and mark of distinction.

To delve deeper, and returning to the 1993-4 study, we feel it is worth examining closely the elements of the aspect of teaching that was the focus of the academics' efforts and attention: course delivery (and the preparation that underpinned its quality). What elements distinguish this from the other aspects of teaching in its widest sense - extra-class professional interaction with students - which many of the academics were ambivalent about, or even wished to avoid? Their lower prioritisation of such interaction implies that it was not ideological notions that influenced these academics' behavior and attitudes: altruistically-based notions such as: service provision; knowledge transmission; or empowerment of others (e.g. through self-esteem or self-efficacy building). Some other force must have driven them to want to perform well in front of a class or lecture audience.

Here we have a clue: performing in front of an audience. Course delivery requires an audience and may be perceived as a performance, whereas other interaction generally involves only an interlocutor and is typically perceived as a consultation. Course delivery carries with it an expectation that the deliverer will 'perform'; will take the initiative and take a lead (even if this involves delegating leading roles to others). Consultative interaction, on the other hand, generally carries with it, at most, an expectation that the academic will provide answers or convey information or knowledge, but in what will most often be a responsive manner, rather than an initiative-taking, leading, manner. Most significantly, course delivery is a recognised medium for performance evaluation; it has 'judgeability'. It is a high-exposure form of performance: a forum or medium for exhibiting one's craft, through the relatively public display of skills, knowledge and talent. When they deliver seminars and lectures academics know that a 'good show' will be talked about by the critics - the student audience. Reputations are made and lost on the stage of seminar or lecture delivery. Course delivery, therefore, is a high-risk activity to those who value their professional reputations. Yet, as with any high-risk activity, the potential benefits are great. Consultative interaction, on the other hand, is a comparatively low-exposure and lowrisk activity, but, more significantly, it provides far fewer opportunities to shine - at least in front of a sizeable crowd.

But why should research-focused academics be concerned about their reputations as effective teachers? Moreover, why should they be concerned about their reputations with a constituency whose standing and status are relatively low within the university organisational hierarchy (indeed, were more so at the time of the study, when the power of the student as consumer had not yet fully taken hold as a notion in the minds of UK academics in general) and whose views and opinions are relatively insignificant to them academics? The answer to these questions, we believe, lies in consideration of the potency of self-esteem and self-efficacy as drivers of human behavior and influences on attitudes.

Self-esteem and self-efficacy: concepts and causal forces

Self-efficacy reflects a person's appraisal of her/ his ability to perform (Webb and Sheeran, 2005). In relation to teachers, Zembylas and Papanastasiou (2005) define it more specifically as 'the perception of having the skills and ability to help students learn' ( $p .437$ ). Most commonly-applied is Bandura's (2000) definition of self-efficacy as an individual's judgment of her/his capability to organize and execute the courses of action required to attain designated types of performances. He writes: 'Perceived self-efficacy is a belief that one can perform using one's skills and abilities adequately in a certain circumstance' ( $p p$. 
36-37). Self-efficacy is subjectively-determined. It is about belief in oneself; in one's abilities and capacity, rather than in externally-imposed evaluations of these.

Self-efficacy has been shown to have a bi-directional relationship to self-esteem: efficacy expectations to perform a given task could influence perceptions of self-esteem when the success/failure is heavily tied in with self-worth (Bandura, 2000), and the evaluations of self-worth (self-esteem) could imply changes in self-efficacy. If a person has high levels of self-efficacy in relation to tasks within an occupation in which s/he has invested much selfworth then there is likely to be a positive correlation between self-esteem and self-efficacy (Dodgson \& Wood, 1998; Lane, Jones, \& Stevens, 2002).

Self-esteem is considered a complex construct (Clegg et al., 2006), with almost as many definitions of it available as there are studies of what influences it. Some definitions treat it as a sense or experience (e.g. James, 1860); some as an attitude (e.g. Rosenberg, 1979); some as a process (e.g. Mruk, 1995); and some as an evaluation (e.g. Coopersmith, 1967). Within his hierarchy of human needs Maslow (1954) identifies self-esteem as a driving force generating motivation. We interpret self-esteem as an individual's evaluation of her/his selfworth in relation to capacity for specific purposes. In the context of our discussion here, we apply this interpretation specifically to consideration of academics' evaluations of their professional self-worth: as researchers and teachers.

\section{Research-focused Academics: Self-efficacy and Self-esteem as Bases for Motivation to Teach Effectively}

Postareff et al. (2008) observe that research into university teachers' self-efficacy beliefs is scarce, and, indeed, we have found no studies that identify self-efficacy as a key driver underpinning the desire to teach effectively. Bailey (1999) researched academics' motivation and self-efficacy in relation to research and teaching, but his focus does not align precisely with the issues that we incorporate into our analysis here: issues that are concerned with research-focused academics' teaching performance and its potential impact upon their self-esteem.

Conventionally self-esteem and self-efficacy are measured by instruments designed for that purpose. These include, for example, the Rosenberg Self-Esteem Scale (1965) and the Coopersmith Self-Esteem Inventory (1967). Rosenberg's scale was originally developed to measure adolescents' global feelings of self-worth or self-acceptance, and is generally considered the standard against which other measures of self-esteem are compared. Similarly, self-efficacy measurement instruments include Postareff et al's (2008) four-item scale that was adapted from Pintrich's (1998) motivation model for learning (cited in Trigwell et al, 2004).

Since neither self-esteem nor self-efficacy was a focus of the original research they were not measured in the 1993-4 study. Our current feasibility determined analysis therefore involves making informed and reasonable estimates of these beliefs held within the sample of eighteen academics. We fully accept that this analysis is fraught with reliability- and validity-related limitations and that it represents reasoned conjecture, rather than scientific robustness. In this respect this paper is as much of an opinion piece as a research report. In effect, it presents a hypothesis. Yet, based on brief outlines of it presented to them, the 2009 follow-up sample supported this hypothesis; two of them, moreover, claimed to have read in full the first version of this paper which was sent to them, and to have found our hypothesis 'very credible' and 'compelling'. The reasoning that underpins our opinions - 
What Drives Research-focused University A cademics

our hypothesis - is presented below.

The driving force(s): achievement, self-efficacy and self-esteem

The academics in question, enjoying the kudos of being employed by one of the UK's top research-intensive universities, and, moreover, each with at least a respectable - and in some cases an outstanding - research profile, are likely to hold reasonably, or even very, high self-esteem beliefs. They are some of the UK's leading academics; their institutional affiliation places them in the top echelons of the UK - and, in some cases, the international - research community. These are, by most standards, high-achievers. 1993-4 interview data revealed most of them to be performance-driven and performance-aware. Some were clearly workaholics, most were perfectionists, and all were anxious to maintain standards and, in many cases, to excel. This desire to excel was not confined to research activity, even though research was prioritized by them. The desire to excel - to be considered highly competent at whatever they did in their professional lives - was the driving force behind their desire to be recognized as effective teachers. Teaching well - well enough to stand out from the crowd - was a vehicle for their feeling a sense of achievement. This sense of achievement had the potential to increase their self-efficacy beliefs, which, in turn, contributed to the enhancement of their self-esteem. The bottom line was that they were driven by self-esteem enhancement needs. In the professional forum in which they performed, self-esteem is enhanced by observable academic performance, both as a researcher and as a teacher. These academics simply could not bring themselves to teach indifferently or badly; this was not part of their persona. One of us (Evans, 2001) has identified self-conception and self-image as one of six key issues that matter to academics in their work contexts. Their skills as teachers were, we suggest, integral to these eighteen academics' professional self-conceptions.

\section{Self-efficacy, Self-esteem and Motivation: Wider I mplications}

Our hypothesis, then, is that motivation to perform stems fundamentally from self-esteem needs (Maslow, 1954), which are reinforced by self-efficacy beliefs. Yet, recognizing its feasibility, we consider how this untested hypothesis may inform our understanding of professional development in higher education.

One of us (Evans, 2008a) has developed an ontological model of professional development that identifies three constituent elements: functional development, attitudinal development and intellectual development, each of which has three further dimensions. It has been argued (Evans, 2008b) that the most effective professional development involves not only functional development (i.e. productive, procedural and/or processual change) but also attitudinal development (i.e. perceptional, evaluative and motivational change), which ensures that the changes to their ways of working that people make or are instructed to make are underpinned by a conviction that these are, in fact changes for the better. Our hypothesis implies that the evaluative change that is a dimension of attitudinal development - that is, change in relation to what things people value and how much they value them goes deeper than relating to activities and job components, such as teaching or research. Thus the attitudinal component of professional development is not simply a matter of changes to the value that people attach to, say, teaching, or to how they perceive teaching (perceptional change), it is about the fundamental values and perceptions that underpin these surface values. In the cases of our academics, these fundamental values were, we suggest, their self-efficacy beliefs within the context of their professional self-conceptions, which, in turn, were valued because they fed into self-esteem. 
Applied to professional development practice, understanding of this is a potentially powerful tool. It means that professional development practitioners may look to the self-esteem of their 'developees' for clues about how best to trigger motives to develop: motives that may enhance self-efficacy beliefs, for example, and lead individuals toward opportunities for selfesteem-enhancing achievement. Understanding others' self-esteem may involve informed conjecture, or it may be based on more scientific measures, but, either way, it must surely qualify as the basic tenet for successful faculty development. As Dale Carnegie observed in his world famous classic (2006, pp. 20-21), 'If you tell me how you get your feelings of importance, I'll tell you what you are. That determines your character. That is the most significant thing about you.' It is this desire to feel important, through the self-efficacy that feeds self-esteem, that makes people tick.

\section{References}

Bailey, J. G. (1999). Academics' motivation and self-efficacy for teaching and research. Higher Education Research \& Development, 18(3), 343-359.

Bandura, A. (2000). Self-efficacy: The exercise of control. New York: W. H. Freeman and Company.

Becher, T. (1989). Academic tribes and territories. Intellectual enquiry and the cultures of disciplines. Bury St. Edmunds, Suffolk: The Society for Research into Higher Education \& Open University Press.

Boshier, R. (2009). Why is the scholarship of teaching and learning such a hard sell? Higher Education Research \& Development, 28 (1), 1-15.

Carnegie, D. (2000). How to win friends and influence people. London: Vermilion

Clegg, S., Bradley, S. and Smith, S. (2006). 'I 've had to swallow my pride': help seeking and self-esteem. Higher Education Research \& Development, 25 (2), 101-113

Coopersmith, S. (1981). The antecedents of self-esteem. Palo Alto, CA: Consulting Psychologists Press.

Deem, R. and Lucas, L. (2007). Research and teaching cultures in two contrasting UK policy contexts: academic life in education departments in five English and Scottish universities. Higher Education, 54 (1), 115-133

Dodgson, P. G., \& Wood, J. V. (1998). Self-esteem and the cognitive accessibility of strengths and weaknesses after failure. Journal of Personality and Social Psychology, 75(1), 178-197.

Evans, L. (1998). Teacher morale, job satisfaction and motivation. London: Paul Chapman.

Evans, L., \& Abbott, I. (1998). Teaching and learning in higher education. London: Cassell. 
Evans, L. (2001). Delving deeper into morale, job satisfaction and motivation among education professionals: Re-examining the leadership dimension. Educational Management and Administration, 29(3), 291-306.

Evans, L. (2002). Reflective practice in educational research: developing advanced skills. London: Continuum.

Evans, L. (2008a). What is teacher development and how is it achieved? Ontological and processual models. Paper presented within the symposium, "Issues in European teacher development: linking theory and practice," at the European Conference on Educational Research, University of Gothenburg, September $12^{\text {th }} 2008$, published on Education-line: http: // www.leeds. ac.uk/educol/documents/175518. pdf

Evans, L. (2008b). Professionalism, professionality and the development of education professionals. British J ournal of Educational Studies, 56 (1), 20-30

Halsey, A.H., \& Trow, M.A. (1971). The British academics. London: Faber and Faber.

Herzberg, F. (1968). One more time: How do you motivate employees? Harvard Business Review, 46(1), 53-62.

James, W. (1980). Principles of psychology. New York: Holt.

Lane, A. M., Jones, L., \& Stevens, M. (2002). Coping with failure: The effects of self-esteem and coping on changes in self-efficacy. J ournal of Sport Behavior, 25, 331-345.

Maslow, A.H. (1954). Motivation and personality. New York: Harper and Row.

Macfarlane, B. \& Hughes, G. (2009). Turning teachers into academics? The role of educational development in fostering synergy between teaching and research. Innovations in Education and Teaching International, 46(1), 5-14.

Mruk, C. (1995). Self-esteem: Research, theory and practice. New York: Springer Publishing Company.

Postareff, L., Lindblom-Ylänne, S. \& Nevgi, A. (2008). A follow-up study of the effect of pedagogical training on teaching in higher education, Higher Education, 56(1), 29-43.

Rosenberg, M. (1965). Society and the adolescent self-image. Princeton, NJ: Princeton University Press.

Skelton, C. (2005). The 'self-interested' woman academic: a consideration of Beck's model of the 'individualised individual'. British J ournal of Sociology of Education, 26 (1), 5- 16.

Steers, R. M., Porter, L. W., \& Bigley, G. A. (1996). Motivation and leadership at work. New York: McGraw-Hill.

Trigwell, K., Ashwin, P., Lindblom-Ylänne, S. \& Nevgi, A. (2004). Variation in approaches to university teaching: The role of regulation and motivation. Paper presented at the EARLI SIG Higher Education Conference, Baltic Sea. 
Webb, T. L., \& Sheeran, P. (2005). Integrating concepts from goal theories to understand the achievement of personal goals. European J ournal of Social Psychology, 35(1), 69-96.

Wright, M. (2005). Always at odds? congruence in faculty beliefs about teaching at a research university. The J ournal of Higher Education, 76 (3), 331-353.

Zembylas, M. and Papanastasiou, E. (2005) Modeling teacher empowerment: The role of job satisfaction. Educational Research and Evaluation, 11 (5), 433-4

\footnotetext{
'In view of the difficulties associated with accurately defining 'learning', and of the debate (current at the time) centred on the distinction between deep and surface learning, the term 'study-related' was adopted on the basis of better representing the research purpose and scope.

ii Pseudonyms are used in all references to the research sample.

iii An association, led by Leeds University's vice chancellor, Professor Michael Arthur, of 20 major research-intensive universities of the UK (http://www.russellgroup.ac.uk)
} 